\title{
GCU
}

Glasgow Caledonian

University

University for the Common Good

\section{The clinical- and cost-effectiveness of functional electrical stimulation and ankle-foot orthoses for foot drop in Multiple Sclerosis: a multicentre randomized trial}

Renfrew, Linda (Miller); Paul, Lorna; McFadyen, Angus; Rafferty, Danny; Mosley, Owen; Lord, Anna C.; Bowers, Roy; Mattison, Paul

Published in:

Clinical Rehabilitation

DOI:

$10.1177 / 0269215519842254$

Publication date:

2019

Document Version

Author accepted manuscript

Link to publication in ResearchOnline

Citation for published version (Harvard):

Renfrew, L, Paul, L, McFadyen, A, Rafferty, D, Mosley, O, Lord, AC, Bowers, R \& Mattison, P 2019, 'The clinical- and cost-effectiveness of functional electrical stimulation and ankle-foot orthoses for foot drop in Multiple Sclerosis: a multicentre randomized trial', Clinical Rehabilitation, vol. 33, no. 7, pp. 1150-1162.

https://doi.org/10.1177/0269215519842254

\section{General rights}

Copyright and moral rights for the publications made accessible in the public portal are retained by the authors and/or other copyright owners and it is a condition of accessing publications that users recognise and abide by the legal requirements associated with these rights.

Take down policy

If you believe that this document breaches copyright please view our takedown policy at https://edshare.gcu.ac.uk/id/eprint/5179 for details of how to contact us. 
1 The clinical and cost effectiveness of functional electrical stimulation and

2 ankle-foot orthoses for foot drop in Multiple Sclerosis: a multicentre randomised trial

4

5 6 Sclerosis. ${ }^{1}$ Foot drop, a frequently occurring problem in Multiple Sclerosis presents

\section{Introduction}

Impairment of walking ability is a significant concern for $85 \%$ of people with Multiple as a reduction in dorsiflexion during heel strike and the swing phase of walking, resulting in poor foot clearance, increasing the risks of trips and falls and impacting on health-related quality of life. ${ }^{1}$

Two assistive devices, ankle-foot orthoses and functional electrical stimulation are commonly used in the treatment of foot drop. Ankle-foot orthosis, a polypropylene device worn on the lower leg and foot, limits the range of motion at the ankle and aids foot clearance. ${ }^{2}$ Functional electrical stimulation, delivers electrical stimulation applied to the common peroneal nerve by means of surface or implanted electrodes, contracting the anterior tibialis muscle during the swing phase of gait. ${ }^{3}$

The effects of both devices on walking can be described as orthotic (the difference walking with the device compared to without), or therapeutic (the difference walking without the device over time). There is growing evidence of positive initial and ongoing orthotic effects of functional electrical stimulation. ${ }^{4}$ Despite ankle-foot orthoses being considered as usual care in the United Kingdom, few studies have investigated their impact on gait in Multiple Sclerosis ${ }^{5,6}$ and only three small studies have compared the effects of both devices. ${ }^{7-9}$ The cost benefit of functional electrical stimulation has been investigated in Multiple Sclerosis ${ }^{10,11}$, however no comparison between these devices has been undertaken. 
The primary aim of our study was to compare the clinical and cost effectiveness of ankle-foot orthoses and functional electrical stimulation over 12 months in people with Multiple Sclerosis presenting with foot drop.

\section{Methods}

This study was prospectively registered with the UK Clinical Trials Gateway (Identifier: 15884) https://www.ukctg.nihr.ac.uk/clinical-trials/search-for-a-clinicaltrial/. The study was funded by the Multiple Sclerosis Society UK (grant reference: 001). It commenced on $1^{\text {st }}$ April 2014 and was completed on $31^{\text {st }}$ March 2018. Ethical approval was granted by the West of Scotland Research Ethics Committee (14/WS/0014) and the study was sponsored by NHS Ayrshire and Arran Research and Development department. A fully powered, multicentre, non-blinded, randomised trial design was employed.

Potential participants known to Multiple Sclerosis healthcare practitioners working across seven out-patient centres in Scotland; Ayrshire \& Arran, Greater Glasgow \& Clyde, Dumfries and Galloway, Lanarkshire, Lothian, Fife and Tayside, were informed of the study and issued with a participant information sheet. Potential participants contacted the researchers if they were interested in participating. Participants required to have; a clinical diagnosis of Multiple Sclerosis, persistent foot drop (lasting a minimum of 3 months) observed during a 5-minute walk test, stable disease (no change in the Extended Disability Status Score ${ }^{12}$ or relapse in previous 3 months), $5^{\circ}$ of passive dorsiflexion, and tolerance of functional electrical stimulation. Participants were excluded if they had; previously used functional electrical stimulation or an ankle-foot orthosis for foot drop, moderate to severe cognitive impairment (scored $<26$, Montreal Cognitive Assessment ${ }^{13}$ ), foot drop due 
50 to other disorders, other conditions significantly affecting gait, contraindications to

Potential participants were screened for eligibility, and written informed consent was gained prior to randomisation. Participants were randomly assigned (1:1) to receive an ankle-foot orthosis or functional electrical stimulation device, by selecting the next envelope from eighty-five randomly ordered prefilled sealed opaque envelopes.

Demographics were collected; age, gender, Multiple Sclerosis subtype and time since diagnosis. Disability was determined by the Extended Disability Status Score by an unblinded assessor trained in the Neurostatus Scoring System. ${ }^{14}$

Outcome measures were administered by two unblinded assessors ( $R H$ and $A L$ ) at baseline (0), 3, 6 and 12 months, except for the Psychological Impact of Assistive Devices Score ${ }^{15}$ which was administered at twelve months only. The primary outcome was walking speed as measured by the 5 -minute self-selected walk test. Participants walked twice, once with their device and once without, resting for 20 minutes between. The order of testing was randomised between participants but was kept consistent for each participant throughout the trial. Participants walked at their preferred walking speed around a $9.5 \mathrm{~m}$ elliptical course for 5 minutes, resulting in a 10-meter shuttle length. The total distance walked was recorded and the mean walking speed $(\mathrm{m} / \mathrm{s})$ calculated. This protocol has been used previously by our group. ${ }^{16-18}$ 
74 Two further secondary walking outcomes; the oxygen cost of walking and Timed 25

75 Foot Walk ${ }^{19}$ were included. The oxygen cost of walking was measured during the 5minute self-selected walk test. Participants wore the COSMED K4b2 (COSMED, Rome, Italy) portable gas analysis system, a facemask (Hans Rudolph Inc., Kansas City, MO, USA) and Polar heart-rate monitor (Polar, Finland). Calibration was undertaken prior to each assessment and participants sat for 5 minutes prior to the test to ensure resting metabolism was established. The oxygen uptake per kilogram body weight $\left(\mathrm{mL} \mathrm{min}^{-1} \mathrm{~kg}^{-1}\right)$ recorded between minutes three and four of the walk test was used to determine the oxygen cost per unit distance walked $\left(\mathrm{mL} \mathrm{min}^{-1} \mathrm{~kg}^{-1} \mathrm{~m}^{-1}\right)$, The COSMED system is a valid system for measuring oxygen uptake in healthy adults. ${ }^{20}$ For the Timed 25 Foot Walk participants walked along a 25 foot course "as quickly as possible, but safely". The test was repeated four times, twice with and twice without the device. The time taken to complete the walks was recorded using a stop watch and the mean time for each pair of walks was used to calculate gait speed $(\mathrm{m} / \mathrm{s})$.

Other secondary patient reported outcome measures included; the Multiple Sclerosis Impact Scale-29 ${ }^{21}$, Multiple Sclerosis Walking scale-12 ${ }^{22}$, Modified Fatigue Impact Scale ${ }^{23}$, Activities-specific Balance and Confidence Scale ${ }^{24}$, Euroquol five-dimension five-level questionnaire (EQ-5D-5L) ${ }^{24}$ and Psychological Impact of Assistive Devices Scale. ${ }^{15}$ The Multiple Sclerosis Impact scale-29 has two sub scales; physical and psychological, with higher scores indicating a greater physical and psychological impact of Multiple Sclerosis on an individual's life. The Psychological Impact of Assistive Devices scale consists of three subscales; Competence (C), Adaptability (A), and Self-Esteem (SE) which measure the impact of assistive devices on 
99 functional independence, well-being, and quality of life.$^{26}$ The EQ-5D-5L consists of a visual analogue scale of perceived health from zero to one hundred and a questionnaire, the results from which were converted to a utility index, which was used to calculate a health outcome measure, quality-adjusted life years.

Participants randomised to the usual care group were fitted with a custom-made, solid, ankle-foot orthosis by an orthotist, within four weeks of their initial assessment.

The recommendations made by the Best Practice Statement for ankle-foot orthoses following stroke were applied. ${ }^{27}$ The orthoses were made with $5 \mathrm{~mm}$ homopolymer polypropylene, trim lines were anterior to the malleoli and reinforcements added to the ankle section as required. The angle of the tibia was inclined forward, approximately $10^{\circ}$ to vertical and each orthosis was 'tuned' by the addition or removal of small heel wedges.

Participants randomised to the functional electrical stimulation group were assessed and fitted with an Odstock Dropped Foot Stimulator Pace (OML, Salisbury) device by a physiotherapist experienced in functional electrical stimulation (AL). Wired heel switches and a stimulation frequency of $40 \mathrm{~Hz}$ were applied. Electrode position, pulse width, waveform and ramping parameters were adjusted for each participant in order to achieve a comfortable and efficient muscle contraction. The current amplitude ranged from 7 to $72 \mathrm{~mA}$ (mean=40mA). Participants in both groups were instructed to gradually increase the wear of their devices over the first few 6 weeks. 
123 Data from the 5-minute self-selected walk test collected from our initial study ${ }^{5}$ was applied to determine the sample size. A minimum of thirty-seven participants were required to detect a change of at least $75 \%$ of 1 standard deviation value $(0.16 \mathrm{~m} / \mathrm{s})$ to achieve a power of $90 \%$ at a $5 \%$ level of significance. Eighty-five participants were recruited allowing for an approximate $15 \%$ attrition rate.

Descriptive statistics for demographic data are presented as means and standard deviations unless otherwise indicated. A repeated measures ANOVA model was employed to analyse the outcome variables where the main factors, Group (anklefoot orthoses/functional electrical stimulation), Time (Baseline (0), 3, 6, 12 months) and for the speed and oxygen cost of walking measures, the Condition (with/without device) and their interactions. The estimated means, standard errors and estimated differences were calculated to inform the ongoing and total orthotic effects and the therapeutic effect on the objective walking outcomes. A Restricted Maximum Likelihood approach to fitting mixed models was employed to allow intention to treat assumptions to cope with missing data. All analysis was performed on IBM SPSS v24, using a $5 \%$ level of significance.

A cost-utility analysis was performed to compare the value for money of functional electrical stimulation with ankle-foot orthoses (usual care). A National Health Service and Personal Social Services perspective analyses was adopted and a discount rate of $3.5 \%$ to future costs and health benefits was applied as recommended by the National Institute for Clinical Excellence. ${ }^{28}$ Equipment costs for both devices were derived from purchase costs at the time of the study. National Health Service staff costs were based on time spent delivering the interventions during the clinical trial, 
following interviews with the clinicians involved. The staff time was then multiplied by the relevant Information Services Division unit cost. The EQ-5D-5L data was converted to a utility index using a published algorithm ${ }^{29}$ and analysis applied the area under the curve method to determine quality-adjusted life years. Missing values were accounted for by carrying forward the last data point and drop outs were assumed to revert to an average of the baseline values to capture expected disease progression. The analysis adopted a time horizon of two years to determine costeffectiveness for a further year beyond the trial. The analysis assumes that qualityadjusted life years estimates derived over the first year are maintained for the additional 12 months. Uncertainty was evaluated by undertaking a sensitivity analysis, by varying a number of parameters by up to $10 \%$. Several scenarios were analysed to test the sensitivity of the model to changes in structural assumptions. The base case results are presented as an incremental cost-effectiveness ratio. An incremental cost-effectiveness ratio below the standard threshold of $£ 20,000$ $(€ 22962.00)-£ 30,000(€ 34443)$ per quality-adjusted life year is indicative that an intervention is cost-effective. ${ }^{30}$ The incremental cost-effectiveness ratio for functional electrical stimulation was calculated using the following standard formula:

$$
\frac{\text { Total cost of treatment FES - Total cost of treatment AFO }}{\text { Total QALYS of treatment FES - Total QALYs of treatment AFO }}
$$

Abbreviations- FES: functional electrical stimulation; AFO: ankle-foot orthoses; QALYs: quality-adjusted life years

\section{Results}

Eighty-five participants met the criteria for inclusion and consented to participate in the study between September 2014 and January 2017 (Figure 1). Five participants withdrew between the screening and assessment visit. Seventy-nine participants 
completed the baseline assessment and were included in subsequent analysis. The recruitment and flow of patients through the study is shown in Figure 1, and the baseline demographic data are detailed in Table 1. Thirty-seven participants dropped out over the course of the study and although there was no statistically significant difference in drop-out rates between the groups, the proportion was higher in the ankle-foot orthoses group.

Insert Figure 1 near here

Insert Table 1 near here

Table 2 presents the data for all outcomes, for both groups, at all assessment points $(0,3,6,12$ months) and the results for the repeated measures ANOVA model employed for all outcomes.

Impact of devices on measures of walking performance

For the primary outcome measure, walking speed as measured by the 5-minute selfselected walk test, a significant difference was observed between the groups $(p=0.005)$ with the functional electrical stimulation group consistently walking faster at all assessment points. Over the 12 months a significant improvement occurred in both groups $(p<0.001)$, although the groups changed differently over this time $(p=0.028)$. The functional electrical stimulation group improved steadily for the first 6 months then declined, whereas changes in the ankle-foot orthoses group fluctuated over 12 months. There was no significant difference between the groups with regards to the effects of the devices. 
197 For the Timed 25 Foot Walk the functional electrical stimulation group walked faster overall compared to the ankle-foot orthoses group $(p=0.043)$. There was no significant difference between the groups, nor did the groups react differently over the 12 months. There was a significant change in oxygen cost of walking at 12 months $(p=0.002)$ for both groups, however there was no difference between the groups.

Insert Table 2 here

Impact of devices on Patient Reported Outcome Measures

Significant improvements in the physical sub-scale of the Multiple Sclerosis Impact Scale $(p=0.040)$ and the Multiple Sclerosis Walking scale-12 $(p=0.002)$ were observed and this was most notable at 3 months in both groups respectively $(p=0.045 ; p<0.001)$. There were no differences between the groups for Patient Reported Outcome Measures, except for all sub scales of the Psychological Impact of Assistive Devices Scale, where the functional electrical stimulation group demonstrated significantly higher scores for Competence $(p=0.016)$, Adaptability $(p=0.001)$ and Self-Esteem $(p=0.006)$ at 12 months.

Orthotic and therapeutic effects on the speed and oxygen cost of walking

Clinically significant effects were determined by an observed increase in walking clinically significant ongoing orthotic effect for both walk tests was demonstrated in 
the functional electrical stimulation, but not the ankle-foot orthoses group (Table 3).

221 A clinically significant total orthotic effect on the primary walking outcome measure was noted in the ankle-foot orthoses, but not the functional electrical stimulation group at 12 months.

224 There was a negative total orthotic and therapeutic effect on oxygen cost of walking with both devices, except for the ankle-foot orthoses at 12 months where a positive total orthotic effect was observed.

Insert Table 3 here

Cost effectiveness

The total quality-adjusted life years were higher for functional electrical stimulation than ankle-foot orthoses (Table 4). Further deterministic sensitivity and scenario analysis indicated that the base case incremental cost-effectiveness ratio in the twoyear model was relatively robust to changes in parameter values or structural assumptions.

Insert Table 4 here

\section{Discussion}

Both devices demonstrated improvements in walking speed at 12 months, although there were no significant differences in their effects. There were many drop outs over

242 the course of the study and the proportion was higher for ankle-foot orthoses, although there was no statistically significant difference between the groups. The 
non-significant positive ongoing orthotic effects observed with functional electrical stimulation were of a similar magnitude to the results previously published in a metaanalysis from our group with respect to the combined long walk (i.e. $0.04 \mathrm{~m} / \mathrm{s}$ ), but not the short walking tests (i.e. $0.08 \mathrm{~m} / \mathrm{s}$ ). ${ }^{4}$ Two small studies previously investigating the ongoing orthotic effect of ankle-foot orthoses on walking speed reported inconclusive results. ${ }^{5,6}$ Only three small non randomised studies have previously compared the impact of these two devices on walking outcomes in Multiple Sclerosis. ${ }^{7-9}$ Sheffler et al. ${ }^{7}$ reported mixed results on gait speed $(n=4)$, and a more recent study $(n=20)^{9}$ found no difference between the devices on the speed or energy cost of walking. Street et al. ${ }^{8}$ reported a significant difference in walking speed $(n=40, p=0.03)$ in favour of functional electrical stimulation, however participants issued with functional electrical stimulation had already rejected anklefoot orthoses, potentially biasing results. Such results suggest that devices may offer similar efficacy, or that the walking performance measures selected may not be sensitive enough to detect differences that exist.

No clinically significant therapeutic effects on walking speed were observed in either group, although the pattern of effect was different. Results from a recent metaanalysis comparing the therapeutic effect of both devices in a stroke and cerebral palsy population also reported comparable positive effects. ${ }^{32}$ No previous studies have evaluated therapeutic effects of ankle-foot orthoses in Multiple Sclerosis, however several functional electrical stimulation studies have investigated these effects over shorter time frames ${ }^{33-37}$ with inconclusive results. Our previous metaanalysis reported a deterioration in unstimulated walking speed during long walking tests following 20 weeks of functional electrical stimualtion. ${ }^{4}$ Nevertheless, Street et 
al. ${ }^{35}$ reported a third of participants gained clinically meaningful therapeutic effects, whilst a third experienced a decline in walking over the same time frame. Given the neurodegenerative nature of Multiple Sclerosis it seems unlikely that either device could offer a therapeutic effect over the longer time frame investigated in our study. However, as observed by Street et al. ${ }^{35}$ it may be possible that a sub group of people with Multiple Sclerosis have the potential to experience such effects and we observed small positive therapeutic effects with ankle-foot orthoses at 12 but not 6 months. This finding suggests that changes may take longer than 6 months to develop with ankle-foot orthoses. Further kinematic and neural control studies are required to corroborate these findings and to understand the possible underlying therapeutic mechanisms of these devices in people with Multiple Sclerosis.

There were no significant differences between the devices with regards to their impact on the oxygen cost of walking. To our knowledge only one other study has compared the ongoing orthotic effects of these devices on the energy and efficiency of gait and reported no difference between these devices. ${ }^{9}$ Nevertheless, there were different patterns of effects observed between the groups, with the functional electrical stimulation group demonstrating small non-significant positive orthotic effects throughout, and the ankle-foot orthoses group observing a greater positive total orthotic effect $\left(-0.05 \mathrm{~mL} \mathrm{~min}{ }^{-1} \mathrm{~kg}^{-1} \mathrm{~m}^{-1} ; 14.7 \%\right)$. These results are difficult to interpret. However, they may have been influenced by the lower baseline oxygen cost of walking in the functional electrical stimulation group.

There was no difference between the groups with regards to the patient reported outcomes, except for the Psychological Impact of Assistive Devices Score where 
participants in the functional electrical stimulation group reported significantly higher scores for all three subscales. Two previous studies evaluated the impact of surface $^{34}$ and implantable ${ }^{40}$ functional electrical stimulation on the Psychological Impact of Assistive Devices Score. Scores for the functional electrical stimulation group in the current study (Competence (1.53); Acceptance (1.00); Self Efficacy (1.41)) were similar to those observed by Taylor et al. ${ }^{40}$ (Competence (1.59); Acceptance (1.34); Self Efficacy (1.44)). The Psychological Impact of Assistive Devices Scale has been found to be predictive of device compliance and retention and is responsive to device stigma. ${ }^{41}$ Higher scores observed in the functional electrical stimulation group suggests that device acceptance may be greater than ankle-foot orthoses. Although both devices aim to promote functional autonomy, assistive technology can be viewed as a symbol of disability, a loss of independence and altered self-image. ${ }^{42}$ Some participants in the ankle-foot orthoses group reported that wearing their device emphasised their disability and this may have contributed to the higher rate of device abandonment observed in this group. Squires et al. ${ }^{43}$ suggests that assistive technology needs to meet both the physical and psychological needs of an individual to ensure positive outcomes and continued use. Future studies therefore need to consider the psychological acceptance of a device in addition to its impact on walking outcomes.

Against a background of financial constraints there is a need for evidence of the cost benefits of interventions. Our study indicates that although the upfront costs of functional electrical stimulation are greater than usual care (ankle-foot orthoses), it may be considered as a potentially cost-effective treatment option for foot drop and offers a value for money alternative in Multiple Sclerosis. The incremental cost 
effectiveness ratio for year one and two for functional electrical stimulation were below the National Institute for Health and Care Excellence's conventional thresholds of $£ 20,000(€ 22962)-£ 30,000(€ 34443)$ per quality-adjusted life year. ${ }^{28}$ No previous studies have examined cost effectiveness of functional electrical stimulation exclusively within Multiple Sclerosis or compared the cost effectiveness of these two devices. Two previous economic evaluations which examined the cost effectiveness of functional electrical stimulation in a mixed neurological population reported incremental cost-effectiveness ratios of $£ 25,235$ ( $€ 28972.30$ ) over one year, reducing to $£ 12,431$ ( $€ 14272$ ) over five years ${ }^{10}$ and $£ 15,406$ (€17688) compared to physiotherapy. ${ }^{11}$ An economic report undertaken in 2009 found that functional electrical stimulation was likely to be cost-effective, although data were almost exclusively from studies recruiting stroke participants. ${ }^{44}$ The results of our current economic analysis concur with these previous investigations and suggests that further improvements in cost-effectiveness of the device could be gained with greater compliance, thus offsetting the upfront costs and allowing the benefit of treatment to accrue over the longer term.

This study has several limitations. Despite this study being powered to detect change, the relatively small number of participants recruited and the high overall dropout rates, with a greater loss from the ankle-foot orthoses group, make it difficult to draw definitive conclusions. In addition, the participant, assessor and treatment provider were not blinded, thus ascertainment bias is likely, although such bias may be less relevant with objective outcomes, such as gait speed. ${ }^{45}$ 
The multi-centre design of this study enhances the generalisability of results. However, although the ankle-foot orthoses prescription was standardised, variations did occur across sites. Ankle-foot orthoses specification can influence biomechanical aspects of gait, thus impacting on walking performance outcomes ${ }^{46}$ and device retention. The ankle-foot orthoses prescription employed was based on stroke guidelines and it is not clear whether this prescription was the most appropriate for people with Multiple Sclerosis, particularly those presenting with a less severe foot drop where such a rigid design may have resulted in higher drop outs. Further investigation is required to identify the most appropriate and acceptable prescription. We excluded participants with stance phase instability and reduced passive range of ankle motion, therefore, findings are only applicable to those with mainly swing phase impairments.

Although the 6-minute Walk Test has been found to be an accurate walking performance test to assess the benefits of assistive technology for foot drop in Multiple Sclerosis ${ }^{47}$, the validity and reliability of our primary outcome, the 5-minute self-selected walk test, has not been established. This is a significant limitation of this study.

The inclusion of an economic analysis is a strength. However, analysis did not consider the impact on other healthcare resources, the time horizons were short, and the differences detected in quality-adjusted life years for both devices were small. Therefore, despite undertaking sensitivity and scenario analyses, the results should be treated with caution. 
Results from this randomised trial which to the best of our knowledge is the first and largest study undertaken comparing the clinical and cost effectiveness of two interventions for foot drop in Multiple Sclerosis over 12 months has provided evidence that functional electrical stimulation is a comparable to ankle-foot orthoses with regards to its impact on walking speed and patient reported outcomes. Although this study suggests that functional electrical stimulation may also provide a value for money alternative to usual care, a larger study which includes follow up of device drop outs, and the employment of long-term modelling to explore the cost and quality-adjusted life years of both interventions over the lifetime of a person with Multiple Sclerosis, is required before definitive conclusions can be drawn with regards to the cost effectiveness of functional electrical stimulation. Further investigation as to how both interventions impact on walking, from a biomechanical, muscle activation, neural control and personal perspective is also recommended. ultimately improving outcomes for people with Multiple Sclerosis.

\section{Clinical messages}

- Ankle-foot orthoses and functional electrical stimulation have comparable positive orthotic effects on gait speed in Multiple Sclerosis.

- Despite higher initial upfront costs for functional electrical stimulation, it offers 


\section{Acknowledgements}

The research team would firstly like to thank the Multiple Sclerosis Society, UK for funding this study (grant reference: 001). We would also like to thank the people with Multiple Sclerosis who participated in this study, the Multiple Sclerosis services across Scotland who assisted with recruitment and the orthotists involved from National Health Services in Ayrshire and Arran, Tayside and Lothian. We would like to thank Odstock Medical Limited, Salisbury and Buchannan Orthotics, Glasgow who provided a discount on their products used in the study.

\section{Declaration of Conflicting Interests}

The author(s) declared no potential conflicts of interest with respect to the research, authorship, and/or publication of this article.

\section{References}

1. LaRocca NG. Impact of walking impairment in multiple sclerosis. Patient 2011; 4: 189-201.

2. Michael j. Lower limb orthoses. In: Hsu J, Michael J, Fisk J eds, AAOS Atlas of Orthoses and Assistive Devices. Philadelphia, PA: Mosby; 2008: 343-355.

3. Liberson WT, Holmquest HJ, Scot D, et al. Functional electrotherapy, stimulation of the peroneal nerve synchronised with the swing phase of gait in hemiplegic patients. Arch Phys Med Rehabil 1961; 42: 101-105.

4. Miller L, McFadyen A, Lord AC, et al. Functional Electrical Stimulation for Foot Drop in Multiple Sclerosis: A Systematic Review and Meta-Analysis of the Effect on Gait Speed. Arch Phys Med Rehabil 2017; 98(7): 1435-1452. 
5. Sheffler LR, Hennessey MT, Knutson JS, et al. Functional effect of an ankle foot orthosis on gait in multiple sclerosis: a pilot study. Am J Phys Med Rehab 2008; 87: 26-32.

6. Bregman DJ, De Groot V, Van Diggele P, et al. Polypropylene ankle foot orthoses to overcome drop-foot gait in central neurological patients: a mechanical and functional evaluation. Prosthet and Orthot Int 2010; 34: 293-304.

7. Sheffler LR, Norgan Bailey S, Chae J. Spatiotemporal and kinematic effect of peroneal nerve stimulation versus an ankle-foot orthosis: A case series. Am J Phys Med \& Rehabil 2009; 1(7): 604-611.

8. Street T, Swain I, Taylor P. A comparison between ankle assisted orthotics and Functional Electrical stimulation: a feasibility study. Multiple Sclerosis 2014; 20: 1001

9. Khurana SR, Beranger AG, Felix ER. Perceived exertion is lower when using a functional electrical stimulation neuroprosthesis compared with an ankle-foot orthosis in persons with Multiple Sclerosis. Am J Phys Med \& Rehabil 2017; 96(3): 133-139.

10. Taylor P, Mann G, Jolley C et al. Economic Justification for the Odstock Dropped Foot Stimulator (ODFS); ISPO meeting: 3rd Nov 2007.

11. Taylor $P$, Humphreys $L$, Swain I. The long-term cost-effectiveness of the use of functional electrical stimulation for the correction of dropped foot due to upper motor neuron lesion. J Rehabil Med 2013; 45: 154-160.

12. Kurtzke JF. Rating neurologic impairment in multiple sclerosis: an expanded disability status scale (EDSS). Neurology 1983; 33(11):1444-1452.

13. Nasreddine ZS, Phillips NA, Bédirian V, Charbonneau S, Whitehead V, Collin I, Cummings JL, Chertkow H. The Montreal Cognitive Assessment, MoCA: a brief 
screening tool for mild cognitive impairment. J Am Geriatr Soc 2005; 53(4): 695699.

14. Neurostatus.net, www.neurostatus.net

15. Day $\mathrm{H}$ and Jutai J. Measuring the psychosocial impact of assistive devices: The PIADS. Can J Rehabil 1996; 9(2): 159-168.

16. Paul L, Rafferty D, Young S, et al. The effect of functional electrical stimulation on

18. Miller L, Rafferty D, Paul L, et al. The impact of walking speed on the effects of functional electrical stimulation for foot drop in people with multiple sclerosis. Disabil Rehabil Assist Technol 2016; 11(6): 478-83.

19. Cutter GR, Baier ML, Rudick RA, Cookfair DL, et al. Development of a multiple sclerosis functional composite as a clinical trial outcome measure. Brain 1999; 122: 871-82.

20. McLaughlan JE, King GA, Howley ET, et al. Validation of the COSMED K4b portable metabolic system. Int J Sports Med 2001; 22: 280-284.

21. Hobart J. The Multiple Sclerosis Impact Scale (MSIS 29): A new patient-based outcome measure. Brain 2001; 124: 962-973.

22. Hobart J. Measuring the impact of MS on walking ability. Neurology 2003; 60(1): $31-36$. 
23. Fisk JD, Pontefract A, Ritvo PG, Archibald CJ, Murray TJ. The impact of fatigue on patients with multiple sclerosis. Can J Neurol Sci 1994; 21: 9-14.

24. Powell LE, Myers AM. The Activities-specific Balance Confidence (ABC) Scale. J Gerontol A Biol Sci Med Sci 1995 ;50(1): 28-34.

25. Brazier J, Ratcliffe J, Tsuchiya A, Salomon J. Measuring and Valuing Health Benefits for Economic Evaluation. Oxford: Oxford University Press; 2007

26. Day H, Jutai J, Campbell KA. Development of a scale to measure the psychosocial impact of assistive devices: lessons learned and the road ahead. Disabil Rehabil 2002 15; 24(1-3): 31-37.

27. National Health Service, Quality Improvement Scotland, Best practice statement: use of ankle-foot orthoses following stroke. Edinburgh and Glasgow: National Health Service, Quality Improvement Scotland 2009: 1-60.

28. NICE "The guidelines manual" Process and Methods National NICE available assessing-cost-effectiveness November 2012 available https://www.nice.org.uk/process/pmg6/chapter/assessing-cost-effectiveness

29. Devlin N, Shah K, Feng Y, et al. Valuing health-related quality of life: An EQ-5D5L value set for England. Health Econ 2017; 27(1):7-22.

30. NICE (2015) "carrying NICE over the threshold” NICE 19th February 2015 available https://www.nice.org.uk/news/blog/carrying-nice-over-the-threshold

31. Perera S, Mody SH, Woodman RC, et al. Meaningful change and responsiveness in common physical performance measures in older adults: meaningful change and performance. J Am Geriatr Soc 2006; 54(5): 743-49.

32. Prenton S, Hollands KL, Kenney LPJ, et al. Functional electrical stimulation and ankle foot orthoses provide equivalent therapeutic effects on foot drop: A meta- 
analysis providing direction for future research. J Rehabil Med 2018; Feb 13;50(2):129-139.

33. Barr C, Patritti BL, Bowes R, et al. Orthotic and therapeutic effect of functional electrical stimulation on fatigue induced gait patterns in people with multiple sclerosis. Disabil Rehabil Assist Technol 2017; 12(6): 560-572.

34. Barrett CL, Mann GE, Taylor PN, et al. A randomized trial to investigate the effects of functional electrical stimulation and therapeutic exercise on walking performance for people with multiple sclerosis. Multiple Sclerosis 2009; 15(4): 493-504.

35. Street T, Taylor P, Swain I. The effectiveness of functional electrical stimulation on walking speed, functional walking category and clinically meaningful changes for people with multiple sclerosis. Arch Phys Med Rehabil 2015; 96(4): 667-672.

36. Taylor PN, Burridge JH, Dunkerly AL, et al. Clinical Use of the Odstock Dropped Foot Stimulator: It's Effect on the Speed and Effort of Walking. Arch Phys Med Rehabil 1999; 80(12): 1577-1583.

37. Van der Linden M, Hooper J, Cowan P, et al. Habitual Functional Electrical Stimulation Therapy Improves Gait Kinematics and Walking Performance, but Not Patient-Reported Functional Outcomes, of People with Multiple Sclerosis who Present with Foot-Drop. PLOS ONE 2014a; 9(8): e103368.

38. Taylor P, Barret $C$, Mann $G$, et al. A feasibility study to investigate the effect of functional electrical stimulation and physiotherapy exercise on the quality of gait of people with Multiple Sclerosis. Neuromodulation 2014; 17(1): 75-84.

39. Stein RB, Everaert DG, Thompson AK, et al. Long-term therapeutic and orthotic effect of a foot drop stimulator on walking performance in progressive and 
nonprogressive neurological disorders. Neurorehabil Neural Repair 2010; 24(2): $152-67$.

40. Taylor PN, Wilkinson Hart I, Khan MS, et al. The Correction of Dropped Foot Due to Multiple Sclerosis Using the STIMuSTEP Implanted Dropped Foot Stimulator. Int J MS Care 2016; 18(5): 239-247.

41. Jutai J, Day H. Psychological Impact of Assistive Devices Scale: the assessment of Assistive Technology Outcomes, Effects and Costs. Technol Disabil 2002; 14(3): 107-111.

42. Verza R, Lopes Carvalho ML, Battaglia MA, et al. An interdisciplinary approach to evaluating the need for assistive technology reduces equipment abandonment. Multiple Sclerosis 2006; 12: 88-93.

43. Squires LA, Williams N, Morrison VL. Matching and accepting assistive technology in multiple sclerosis: A focus group study with people with multiple sclerosis, carers and occupational therapists. J Health Psychol 2016:1-15.

44. Centre for Evidence-based Purchasing (CEP), Feb 2010. Economic report: Functional electrical stimulation for drop foot of central neurological origin (CEP 10012). UK: NHS Purchasing and Supply Agency. Available from:

\section{http://www.cedar.wales.nhs.uk/sitesplus/documents/1091/CEP10012\%20FES\%2}

\section{0econ\%20report.pdf}

45. Hróbjartsson A, Thomsen AS, Emanuelsson F, et al. Observer bias in randomised clinical trials with binary outcomes: systematic review with both blinded and non-blinded outcome. BMJ 2012; 27 (344): e1119.

46. Chen $\mathrm{CC}$, Hong WH, Wang CM, et al. Kinematic features of rear-foot motion using anterior and posterior ankle-foot orthoses in stroke patients with hemiplegic gait. Arch Phys Med Rehabil 2010; 91(12): 1862-1868. 
542

543

544

545

546

547

548

549

550

551

552

553

554

555

556

557

558

559

560

561

562

563

47. Andreopoulou G, Mercer T H, van der Linden M L. Walking measures to evaluate assistive technology for foot drop in multiple sclerosis: A systematic review of psychometric properties. Gait Posture 2018; 61: 55-66.

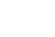

3

(1)

5

6


564 Table 1. Demographic characteristics of participants.

\begin{tabular}{|c|c|c|c|}
\hline & AFO & FES & $p$ \\
\hline $\mathrm{n}$ & 38 & 41 & \\
\hline Mean age [years] & $51.4[11.2]$ & $50.4[10.4]$ & $0.684^{\mathrm{a}}$ \\
\hline Gender \% Male & $52.6 \%$ & $20.0 \%$ & $0.006^{\mathrm{c}}{ }^{\mathrm{a}}$ \\
\hline Type of MS Primary Progressive & $21.1 \%$ & $15.0 \%$ & \\
Secondary Progressive & $26.3 \%$ & $20.0 \%$ & $0.6647^{\mathrm{c}}$ \\
Relapsing Remitting & $42.1 \%$ & $45.0 \%$ & \\
Mnknown & $10.5 \%$ & $20 \%$ & \\
diagnosis [years] & $10.2[10.3]$ & $7.6[8.6]$ & $0.205^{\mathrm{b}}$ \\
\hline Mean Extended Disability & $5.3[1.3]$ & $4.9[1.4]$ & $0.136^{\mathrm{b}}$ \\
Status Scale & & & \\
\hline
\end{tabular}

565 Abbreviations- n: number; AFO: ankle-foot orthoses; FES: functional electrical stimulation;

566 MS: Multiple Sclerosis.

567 Data values are mean [SD] for continuous variables and $\mathrm{n}(\%)$ for categorical variables

568 unless otherwise stated. Between group differences for demographic data (a: t-test, b: Man-

569 Whitney, c: chi-square, *: significant). 
571 Table 2: Means and SD for the primary and secondary outcome measures in the intervention and usual care group at 0,3,6 and 12 months.

\begin{tabular}{|c|c|c|c|c|c|c|c|c|c|c|c|c|}
\hline & \multicolumn{2}{|l|}{$\begin{array}{l}\text { Baseline } \\
\text { (0) }\end{array}$} & \multicolumn{2}{|l|}{$3 \mathrm{mo}$} & \multicolumn{2}{|l|}{$6 \mathrm{mo}$} & \multicolumn{2}{|l|}{$12 \mathrm{mo}$} & \multicolumn{4}{|l|}{$\begin{array}{l}\text { ANOVA } \\
\text { Results }\end{array}$} \\
\hline & AFO & FES & AFO & FES & AFO & FES & AFO & FES & Group & Time & $\begin{array}{l}\text { Group/Time } \\
\text { interaction }\end{array}$ & $\begin{array}{l}\text { Group/with } \\
\text { v without } \\
\text { device }\end{array}$ \\
\hline $5 \mathrm{minSSWT}$ (without) $\mathrm{m} / \mathrm{s}$ & $0.62[0.21]$ & $0.73[0.27]$ & $0.69[0.23]^{\mathrm{a}}$ & $0.75[0.26]^{\mathrm{a}}$ & $0.65[0.25]^{b, c}$ & $0.78[0.27]^{\mathrm{b}, \mathrm{c}}$ & $0.71[0.25]^{\mathrm{d}}$ & $0.73[0.26]^{\mathrm{d}}$ & \multirow[t]{2}{*}{$\mathrm{P}=0.005^{\star}$} & \multirow[t]{2}{*}{$P<0.001^{*}$} & \multirow[t]{2}{*}{$\mathrm{P}=0.028^{*}$} & \multirow[t]{2}{*}{$\mathrm{P}=0.714$} \\
\hline $5 \mathrm{minSSWT}$ (with) $\mathrm{m} / \mathrm{s}$ & $0.61[0.22]$ & $0.74[0.25]$ & $0.72[0.22]^{\mathrm{a}}$ & $0.81[0.26]^{\mathrm{a}}$ & $0.68[0.27]^{b, c}$ & $0.83[0.27]^{b, c}$ & $0.73[0.24]^{\mathrm{d}}$ & $0.79[0.24]^{\mathrm{d}}$ & & & & \\
\hline $25 \mathrm{ftWT}$ (without) $\mathrm{m} / \mathrm{s}$ & $0.86[0.34]$ & $0.94[0.34]$ & $0.89[0.30]$ & $0.95[0.30]$ & $0.98[0.29]$ & $0.93[0.29]$ & $0.96[0.31]$ & $0.95[0.30]$ & \multirow[t]{2}{*}{$\mathrm{P}=0.043^{*}$} & \multirow[t]{2}{*}{$\mathrm{P}=0.279$} & \multirow[t]{2}{*}{$\mathrm{P}=0.310$} & \multirow[t]{2}{*}{$\mathrm{P}=0.571$} \\
\hline $25 \mathrm{ftWT}$ (with) $\mathrm{m} / \mathrm{s}$ & $0.83[0.30]$ & $0.97[0.33]$ & $0.90[0.27]$ & $1.00[0.29]$ & $0.88[0.29]$ & $0.99[0.29]$ & $0.98[0.29]$ & $1.00[0.29]$ & & & & \\
\hline $\mathrm{O}_{2}$ cost (without) $\mathrm{mLmin}^{-1} \mathrm{~kg}^{-1} \mathrm{~m}^{-1}$ & $0.34[0.16]$ & $0.29[0.14]$ & $0.22[0.18]$ & $0.31[0.21]$ & $0.36[0.17]^{\mathrm{e}}$ & $0.31[0.26]^{\mathrm{w}}$ & $0.35[0.21]^{\mathrm{f}, \mathrm{g}}$ & $0.33[0.20]^{1, g}$ & \multirow[t]{2}{*}{$\mathrm{P}=0.177$} & \multirow[t]{2}{*}{$\mathrm{P}=0.002^{*}$} & \multirow[t]{2}{*}{$\mathrm{P}=0.093$} & \multirow[t]{2}{*}{$\mathrm{P}=0.989$} \\
\hline $\mathrm{O}_{2} \operatorname{cost}\left(\right.$ with) $\mathrm{mLmin}^{-1} \mathrm{~kg}^{-1} \mathrm{~m}^{-1}$ & $0.35[0.16]$ & $0.28[0.12]$ & $0.31[0.14]$ & $0.28[0.11]$ & $0.38[0.18]^{e}$ & $0.28[0.23]^{\mathrm{e}}$ & $0.35[0.32]^{\mathrm{t}, \mathrm{g}}$ & $0.29[0.15]^{1,9}$ & & & & \\
\hline MSIS-29 (physical) & $37.0[13.3]$ & $35.7[18.1]$ & $33.8[14.3]^{n}$ & $33.9[16.1]^{n}$ & $31.6[13.0]$ & $34.0[17.7]$ & $33.8[15.2]$ & \begin{tabular}{|l|}
$34.2[17.4]$ \\
\end{tabular} & $\mathrm{P}=0.836$ & $\mathrm{P}=0.040^{*}$ & $\mathrm{P}=0.819$ & \\
\hline MSIS-29 (psych) & $14.0[8.9]$ & $13.0[8.3]$ & $13.8[8.1]$ & $12.6[7.9]$ & $11.6[6.8]$ & $13.0[8.1]$ & $12.5[7.2]$ & 12.2[7.2] & $\mathrm{P}=0.056$ & $P=0.987$ & $\mathrm{P}=0.873$ & \\
\hline MSWS-12 & $33.8[8.3]$ & $30.4[12.1]$ & $29.5[10.3]^{\prime}$ & $27.2[12.0]^{\prime}$ & $31.2[9.4]^{\top}$ & $27.9[11.0]^{\prime}$ & $28.9[11.9]$ & $29.9[12.4]$ & $\mathrm{P}=0.202$ & $P=0.002^{*}$ & $\mathrm{P}=0.243$ & \\
\hline EQ-5D-VAS & $67.7[16.5]$ & $70.2[19.3]$ & $67.7[18.7]$ & $72.5[17.5]$ & $66.0[19.0]$ & $71.5[21.4]$ & $68.8[18.9]$ & $74.3[15.5]$ & $\mathrm{P}=0.169$ & $\mathrm{P}=0.257$ & $\mathrm{P}=0.795$ & \\
\hline MFIS & 11.5[4.1] & $11.7[5.3]$ & $11.3[4.0]$ & $11.1[4.9]$ & $11.0[4.2]$ & $11.2[4.9]$ & $11.3[4.8]$ & $11.9[4.5]$ & $\mathrm{P}=0.888$ & $\mathrm{P}=0.233$ & $\mathrm{P}=0.433$ & \\
\hline $\mathrm{ABC}$ & $50.2[18.9]$ & $54.4[23.6]$ & $51.2[19.4]$ & $56.7[21.4]$ & $52.6[20.5]$ & $56.4[20.9]$ & $52.2[23.5]$ & $53.7[20.3]$ & $\mathrm{P}=0.378$ & $\mathrm{P}=0.934$ & $\mathrm{P}=0.741$ & \\
\hline PIADS C & & & & & & & $0.85[1.01]$ & $1.53[1.05]$ & $\mathrm{P}=0.0016^{*}$ & & & \\
\hline PIADS A & & & & & & & $0.38[0.97]$ & $1.41[0.98]$ & $\mathrm{P}=0.001^{*}$ & & & \\
\hline PIADS SE & & & & & & & $0.45[0.67]$ & $1.00[0.68]$ & $\mathrm{P}=0.006^{*}$ & & & \\
\hline
\end{tabular}

572 Abbreviations- mo: months; AFO: ankle foot orthoses; FES: functional electrical stimulation; 5 minSSWT: 5 minute self-selected walk test: $\mathrm{m} / \mathrm{s}$;

573 meters per second: $25 \mathrm{ftWT}$ : 25 foot walk test; $\mathrm{O} 2$ cost $\left(\mathrm{mLmin}^{-1} \mathrm{~kg}^{-1} \mathrm{~m}^{-1}\right)$; oxygen cost of walking per unit distance walked: MSIS-29 (physical);

574 Multiple Sclerosis Impact Scale-29 physical sub scale: MSIS-29 (psych); Multiple Sclerosis Impact Scale-29 psychological sub scale: MSWS- 
575 12; Multiple Sclerosis walking scale-12: EQ-VAS; Euroqual questionnaire visual analogue scale; MFIS; modified fatigue impact scale; ABC:

576 activities and balance confidence scale; PIADS C: psychological impact of assistive devices scale competence sub scale; PIADS A: 577 adaptability subscale; PIADS SE: self-esteem subscale; *: statistically significant difference detected; a: ANOVA sig time effect 0-3months, $578 p<0.001 ;{ }^{b}$ : ANOVA sig time effect 0-6 months, $p=0.029 ;{ }^{\circ}$ : ANOVA sig time effect 3-6 months, $p=0.028 ;$ : ANOVA sig time effect 3-12 months, $579 p=0.09$; ${ }^{e}$ : ANOVA sig time effect 3-6 months, $p=0.07$; $:$ : ANOVA sig time effect 0-12 months, $p=0.011$; 9 : ANOVA sig time effect 3-12 months, $580 p=0.001 ;{ }^{h}:$ ANOVA sig time effect $0-3$ months, $p=0.045 ;$ ': ANOVA sig time effect $0-3$ months, $p<0.001 ;{ }^{j}$ : ANOVA sig time effect $3-6$ months, $581 \mathrm{p}=0.035$. 
582 Table 3: Estimated means (SE) of initial, ongoing and total orthotic and therapeutic effects of

583 AFO and FES on the 5minSSWT, 25ftWT and the oxygen cost of walking.

\begin{tabular}{|c|c|c|c|c|c|c|}
\hline & \multicolumn{3}{|c|}{ AFO } & \multicolumn{3}{|c|}{ FES } \\
\hline & without & with & $\Delta$ & without & with & $\Delta$ \\
\hline \multicolumn{7}{|l|}{10} \\
\hline $5 \operatorname{minSSWT}(\mathrm{m} / \mathrm{s})$ & $0.63(0.04)$ & $0.61(0.04)$ & -0.02 & $0.73(0.04)$ & $0.74(0.04)$ & +0.01 \\
\hline $25 \mathrm{ftWT}(\mathrm{m} / \mathrm{s})$ & $0.86(0.06)$ & $0.83(0.05)$ & -0.03 & $0.85(0.05)$ & $0.87(0.05)$ & +0.03 \\
\hline $\mathrm{O}_{2} \operatorname{cost}\left(\mathrm{mLmin}^{-1} \mathrm{~kg}^{-1} \mathrm{~m}^{-1}\right)$ & $0.34(0.03)$ & $0.35(0.03)$ & +0.01 & $0.29(0.02)$ & $0.28(0.02)$ & -0.01 \\
\hline \multicolumn{7}{|l|}{$\mathrm{OO} \mathrm{(3 \textrm {mo } )}$} \\
\hline $5 \operatorname{minSSWT}(\mathrm{m} / \mathrm{s})$ & $0.67(0.04)$ & $0.70(0.04)$ & +0.03 & $0.76(0.05)$ & $0.81(0.05)$ & $+0.05^{\mathrm{a}}$ \\
\hline $25 \mathrm{ftWT}(\mathrm{m} / \mathrm{s})$ & $0.86(0.05)$ & $0.87(0.05)$ & +0.01 & $0.95(0.05)$ & $0.99(0.05)$ & +0.04 \\
\hline $\mathrm{O}_{2} \operatorname{cost}\left(\mathrm{mLmin}^{-1} \mathrm{~kg}^{-1} \mathrm{~m}^{-1}\right)$ & $0.33(0.03)$ & $0.31(0.03)$ & -0.02 & $0.32(0.03)$ & $0.29(.03)$ & -0.03 \\
\hline \multicolumn{7}{|l|}{$00(6 \mathrm{mo})$} \\
\hline $5 \operatorname{minSSWT}(\mathrm{m} / \mathrm{s})$ & $0.61(0.04)$ & $0.65(0.04)$ & +0.04 & $0.76(0.04)$ & $0.81(0.04)$ & $+0.05^{\mathrm{a}}$ \\
\hline $25 \mathrm{ftWT}(\mathrm{m} / \mathrm{s})$ & $0.84(0.05)$ & $0.82(0.05)$ & -0.02 & $0.92(0.05)$ & $0.97(0.05)$ & $+0.05^{a}$ \\
\hline $\mathrm{O}_{2} \operatorname{cost}\left(\mathrm{mLmin}^{-1} \mathrm{~kg}^{-1} \mathrm{~m}^{-1}\right)$ & $0.35(0.03)$ & $0.38(0.03)$ & +0.03 & $0.33(0.04)$ & $0.32(0.04)$ & -0.01 \\
\hline \multicolumn{7}{|l|}{$\mathrm{OO} \mathrm{(12 \textrm {mo } )}$} \\
\hline $5 \operatorname{minSSWT}(\mathrm{m} / \mathrm{s})$ & $0.66(0.04)$ & $0.67(0.04)$ & +0.02 & $0.71(0.05)$ & $0.76(0.05)$ & $+0.05^{a}$ \\
\hline $25 \mathrm{ftWT}(\mathrm{m} / \mathrm{s})$ & $0.88(0.06)$ & $0.90(0.06)$ & +0.02 & $0.91(0.05)$ & $0.96(0.05)$ & $+0.05^{a}$ \\
\hline $\mathrm{O}_{2} \operatorname{cost}\left(\mathrm{mLmin}^{-1} \mathrm{~kg}^{-1} \mathrm{~m}^{-1}\right)$ & $0.38(0.05)$ & $0.39(0.05)$ & +0.01 & $0.39(0.05)$ & $0.36(0.05)$ & -0.03 \\
\hline \multicolumn{7}{|l|}{ TO (12mo) } \\
\hline $5 \operatorname{minSSWT}(\mathrm{m} / \mathrm{s})$ & & & $+0.05^{\mathrm{a}}$ & & & +0.03 \\
\hline $25 \mathrm{ftWT}(\mathrm{m} / \mathrm{s})$ & & & +0.04 & & & +0.02 \\
\hline $\begin{array}{l}\mathrm{O}_{2} \operatorname{cost}\left(\mathrm{mLmin}-1 \mathrm{~kg}^{-1} \mathrm{~m}^{-}\right. \\
\left.{ }^{1}\right)\end{array}$ & & & -0.05 & & & +0.07 \\
\hline \multicolumn{7}{|l|}{ Th (6mo) } \\
\hline $5 \operatorname{minSSWT}(\mathrm{m} / \mathrm{s})$ & & & -0.02 & & & +0.03 \\
\hline $25 \mathrm{ftWT}(\mathrm{m} / \mathrm{s})$ & & & -0.02 & & & -0.02 \\
\hline $\begin{array}{l}\mathrm{O}_{2} \operatorname{cost}\left(\mathrm{mLmin}-1 \mathrm{~kg}^{-1} \mathrm{~m}^{-}\right. \\
\left.{ }^{1}\right)\end{array}$ & & & +0.01 & & & +0.04 \\
\hline \multicolumn{7}{|l|}{ Th (12mo) } \\
\hline $5 \operatorname{minSSWT}(\mathrm{m} / \mathrm{s})$ & & & +0.03 & & & -0.02 \\
\hline $25 \mathrm{ftWT}(\mathrm{m} / \mathrm{s})$ & & & +0.02 & & & -0.03 \\
\hline $\mathrm{O}_{2}$ cost & & & +0.04 & & & +0.10 \\
\hline
\end{tabular}

584 Abbreviations- AFO; ankle foot orthoses; FES: functional electrical stimulation; $\Delta=$ effect of

585 estimated means; IO: initial orthotic effect; OO: ongoing orthotic effect; TO (12mth): total

586 orthotic effect at 12 months; Th (12mth): therapeutic effect at 12 months; mo: months;

587 5minSSWT: 5-minute self-selected walk test: $\mathrm{m} / \mathrm{s}$ : meters per second; $25 \mathrm{ftWT}$ : Timed 25 foot

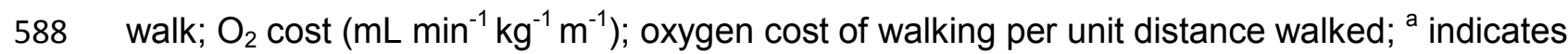

589 a mean change in walking speed of $\geq 0.05 \mathrm{~m} / \mathrm{s}$, considered to be clinically significant. 
591 Table 4: Treatment costs, quality-adjusted life years and incremental cost effectiveness

592 ratio's for both devices over both one and two years. (year two costs represent the

593 cumulative total of year one and year two costs).

\begin{tabular}{|c|c|c|c|c|c|}
\hline \multicolumn{6}{|l|}{ Year 1} \\
\hline Treatment & $\begin{array}{l}\text { Total cost per year } \\
\text { including } \\
\text { equipment and } \\
\text { staff costs }(£ / €)\end{array}$ & $\begin{array}{l}\text { Total } \\
\text { QALYs }\end{array}$ & Inc. cost $(£ / €)$ & $\begin{array}{l}\text { Inc. } \\
\text { QALY }\end{array}$ & $\operatorname{ICER}(£ / €)$ \\
\hline AFO & $579.76 / 665.62$ & 0.65 & & & \\
\hline FES & $1,228.02 / 1409.89$ & 0.68 & $648.26 / 744.27$ & 0.03 & $25,588.96 / 29378.68$ \\
\hline
\end{tabular}

Year 2

\begin{tabular}{|l|l|l|l|l|l|}
\hline & $\begin{array}{l}\text { Total cost per year } \\
\text { including } \\
\text { equipment and } \\
\text { staff costs }(£ / €)\end{array}$ & $\begin{array}{l}\text { Total } \\
\text { QALYs }\end{array}$ & Inc. cost (£/€) & $\begin{array}{l}\text { Inc. } \\
\text { QALY }\end{array}$ & ICER $(£ / €)$ \\
\hline AFO & $723.00 / 830.08$ & 1.31 & & & \\
\hline FES & $1,446.83 / 1661.11$ & 1.36 & $723.83 / 831.03$ & 0.05 & $14,285.92 / 16401.66$ \\
\hline
\end{tabular}

594

595 Abbreviations- AFO; ankle foot orthoses; FES: functional electrical stimulation; inc:

596 incremental; QALY: quality adjusted life year; ICER: incremental cost effectiveness ratio.

597 Values presented are British pounds and euros.

598

599

600

601

602

603

604

605

606

607

608

609

610

611 
Figure 1: Consort diagram.

Abbreviations: AFO: ankle-foot orthoses, FES: functional electrical stimulation

615

\section{Enrolment}

616

617

618

619

620

Allocated to AFO intervention ( $n=43$ )

621

- Received allocated intervention $(n=38)$

Assessed for eligibility $(n=96)$

- Did not receive allocated intervention $(n=5)$

622

- Not happy with group allocation $(n=3)$

- Not happy with AFO (n=2)

623

624

625

- Discontinued intervention due to AFO

626

627 being uncomfortable, too bulky or difficult to accommodate footwear $(n=6)$

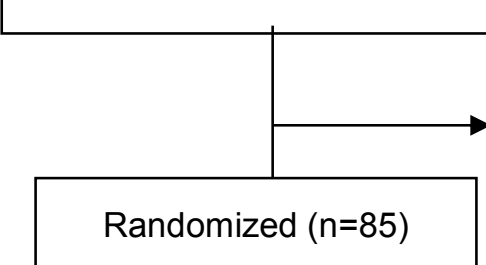

Excluded $(n=11)$

- Didn't meet inclusion criteria $(n=9)$

- Didn't want to be randomised $(n=1)$

- Unable to commit $(n=1)$

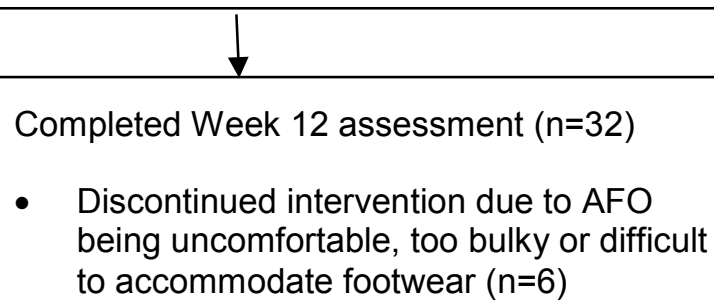

- Missed assessment ( $n=3)$

Completed Week 24 assessment $(n=26)$

- Discontinued intervention $(n=3)$ due to unable to commit to study $(n=1)$, not happy with AFO $(n=1)$, lost contact $(n=1)$

- Discontinued intervention $(n=7)$; not happy with/not using AFO $(n=3)$, disease progression $(n=3)$, unwell $(n=1)$, lost contact $(n=1)$
Allocated to FES intervention $(n=42)$

- Received allocated intervention $(n=41)$

- Did not receive allocated intervention $(n=1)$

- Unable to commit to studv

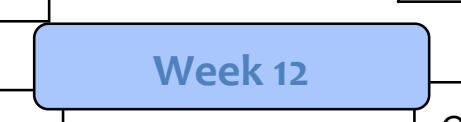

Completed Wk 12 assessment $(n=37)$

- Discontinued intervention $(n=4)$ due to relapse $(n=1)$, unable to commit to study $(n=2)$, disease progression $(n=1)$

- Missed assessment ( $n=3)$

(

Completed Week 24 assessment $(n=37)$

Week 52
Completed Week 52 assessment $(n=31)$

- Discontinued intervention $(n=6)$; lost contact $(n=2)$, relapse $(n=1)$, not finding FES helpful $(n=2)$, increased neuropathic pain preventing use $(n=1)$

- Missed assessment ( $n=1)$ 